\title{
Bradford's law: identification of the core journals for neurosurgery and its subspecialties
}

\author{
Garrett T. Venable, BSc, ${ }^{1}$ Brandon A. Shepherd, BSc, ${ }^{1}$ Christopher M. Loftis, BSc, ${ }^{1}$ \\ S. Gray McClatchy, BSc, ${ }^{2}$ Mallory L. Roberts, BA, ${ }^{1}$ Meghan E. Fillinger, BSc, ${ }^{1}$ James B. Tansey, ${ }^{3}$ \\ and Paul Klimo Jr., MD, MPH4-6
}

${ }^{1}$ College of Medicine and ${ }^{4}$ Department of Neurosurgery, University of Tennessee Health Science Center; ${ }^{3}$ Christian Brothers University; ${ }^{5}$ Semmes-Murphey Neurologic \& Spine Institute; and ${ }^{6}$ Le Bonheur Neuroscience Institute, Le Bonheur Children's Hospital, Memphis, Tennessee; and ${ }^{2}$ College of Medicine, University of Arkansas for Medical Sciences, Little Rock, Arkansas

OBJECTIVE Bradford's law describes the scatter of citations for a given subject or field. It can be used to identify the most highly cited journals for a field or subject. The objective of this study was to use currently accepted formulations of Bradford's law to identify core journals of neurosurgery and neurosurgical subspecialties.

METHODS All original research publications from 2009 to 2013 were analyzed for the top 25 North American academic neurosurgeons from each subspecialty. The top 25 were chosen from a ranked career $h$-index list identified from previous studies. Egghe's formulation and the verbal formulation of Bradford's law were applied to create specific citation density zones and identify the core journals for each subspecialty. The databases were then combined to identify the core journals for all of academic neurosurgery.

RESULTS Using Bradford's verbal law with 4 zone models, the authors were able to identify the core journals of neurosurgery and its subspecialties. The journals found in the most highly cited first zone are presented here as the core journals. For neurosurgery as a whole, the core included the following journals: Journal of Neurosurgery, Neurosurgery, Spine, Stroke, Neurology, American Journal of Neuroradiology, International Journal of Radiation Oncology Biology Physics, and New England Journal of Medicine. The core journals for each subspecialty are presented in the manuscript.

CONCLUSIONS Bradford's law can be used to identify the core journals of neurosurgery and its subspecialties. The core journals vary for each neurosurgical subspecialty, but Journal of Neurosurgery and Neurosurgery are among the core journals for each neurosurgical subspecialty.

http://thejns.org/doi/abs/10.3171/2015.3.JNS15149

KEY WORDS Bradford's law; bibliometrics; h-index; citation analysis; core journals; Scopus; neurosurgery; subspecialties

$\mathrm{P}$ HYSICIANS use a variety of resources to remain current in their field of interest, including conferences, electronic media, periodicals, peer-reviewed journals, and textbooks. ${ }^{22}$ Historically, peer-reviewed journals have been used by physicians to maintain expertise in their particular fields, but this has become increasingly more difficult given the exponential expansion of scientific literature, which is currently doubling in size every 7 years. ${ }^{20,27,28}$ Clinical researchers are faced with the increasing challenge of staying up-to-date on standards of practice and cutting-edge research. All neurosurgical subspecialties benefit from discoveries made in other disciplines, such as molecular biology, neurology, oncology, and radiology, and these discoveries may be more pertinent for one subspecialty than another. For this reason, it would be advantageous for researchers to know which scientific journals, including nonneurosurgical journals, contain the most useful information for general and subspecialty neurosurgeons.

In 1934, Samuel C. Bradford first described how information was scattered for a given subject based on the distribution of references. ${ }^{3}$ Bradford discovered that when equally dividing all references in a given subject into 3 groups, or zones, the citations for the first zone would come from a small "core" group of journals. The second zone would require more journals to achieve the same number of citations, and the third zone exponentially more than the second. In moving from Zone 1 to Zone 3 there is a

ABBREVIATION IF = impact factor.

SUBMITTED January 22, 2015. ACCEPTED March 12, 2015.

INCLUDE WHEN CITING Published online September 4, 2015; DOI: 10.3171/2015.3.JNS15149. 
"diminishing productivity" described by Bradford, which has become known as Bradford's law of scattering, or Bradford's distribution. Figure 1 depicts a graphical representation of Bradford's law. Hjørland and Nicolaisen ${ }^{10}$ noted that Bradford's law has influenced the methodology of building collections, selecting journals indexed in bibliographies, measuring the coverage of bibliographies, solving practical problems related to information seeking and retrieval, and arguing for updated organization of bibliographical work and scientific documentation. Bradford's law of scattering, Lotka's law of scientific productivity, and Zipf's law of word occurrence are the 3 most commonly used principles in bibliometrics.

Core journals have been identified in many fields by using Bradford's law of scattering, including environmental and occupational health, ${ }^{23}$ nursing, ${ }^{24}$ physical and rehabilitation medicine, ${ }^{7}$ physical therapy, ${ }^{6}$ physics, ${ }^{26}$ and science. ${ }^{4}$ In 2013, Madhugiri et al. ${ }^{19}$ were the first to apply Bradford's law of scattering to identify core journals within the field of neurosurgery. They sampled all journal references from the 11 top neurosurgical journals based on impact factor (IF) over a 3-month period, excluding special and focused editions in which many articles about a single specific topic were published. They were able to fit Bradford's law into 3 zones (p) for a total of 182 journals, with the 6 core journals within Zone 1 being Journal of Neurosurgery, Neurosurgery, Spine, Acta Neurochirurgica, Stroke, and Journal of Neurotrauma.$^{19}$ Additionally, in 2014, we applied Bradford's law to the field of pediatric neurosurgery. ${ }^{15}$ We examined all published articles in a 5-year period from the top 25 North American pediatric neurosurgeons based on h-index, as well as the top 25 European pediatric neurosurgeons. Using Bradford's law of scattering, we were able to identify 9 core journals with a Bradford's multiplier of 4 . These journals are as follows: Journal of Neurosurgery, Neurosurgery, Epilepsia, Child's Nervous System, Pediatric Neurosurgery, Neurology, Journal of Clinical Oncology, Cancer Research, and New England Journal of Medicine. ${ }^{15}$

We recently created productivity profiles for nearly all neurosurgical researchers in the US. ${ }^{14}$ Many of these bibliometric indices, particularly the h-index, have been widely applied in neurosurgery. ${ }^{1,8,11-14,17,25,29}$ Using this database, we examined 6 different neurosurgery subspecialties: neurosurgical oncology, peripheral nerve, skull base, spine, stereotactic and functional, and vascular. We identified the top 25 North American neurosurgeons in each of these subspecialties based on their h-index. By applying Bradford's law to journal articles that were referenced by each of those neurosurgeons over a 5-year period (20092013), we identified the core journals for each of the neurosurgical subspecialties. These databases were then combined, including the pediatric neurosurgery database previously reported, ${ }^{30}$ to create citation density zones and identify the core journals for neurosurgery overall.

\section{Methods}

\section{Study Population and Data Retrieval}

Recently we identified the top North American academic neurosurgeons as ranked by h-index..$^{14}$ From this

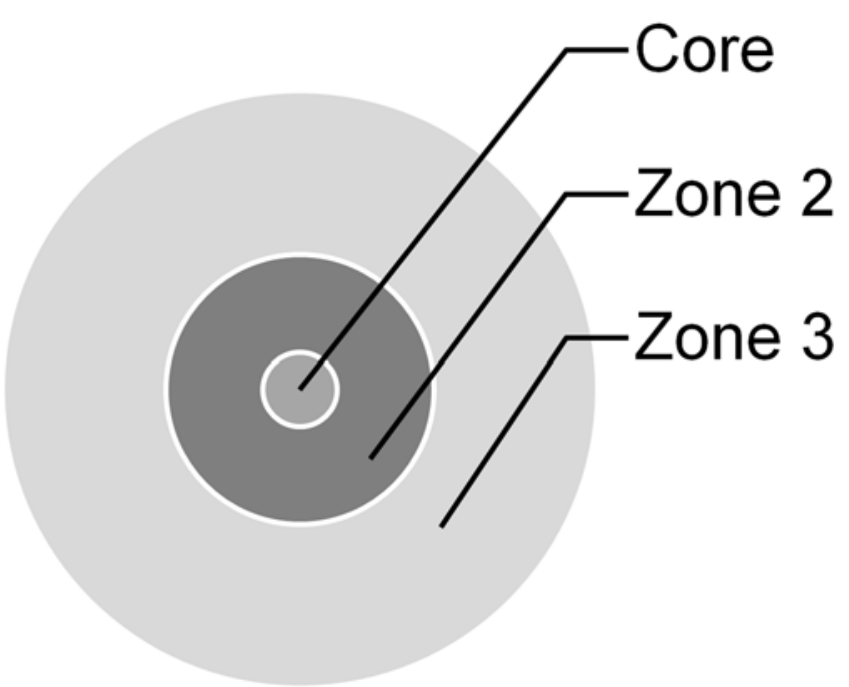

FIG. 1. Graphical depiction of Bradford's law. Each zone carries an equal number of citations, and zone size is equal to the number of journals in that zone.

bibliometric database we identified the top 25 academic neurosurgeons from each of the Society of Neurological Surgeons (SNS) - and Committee on Advanced Subspecialty Training (CAST)-recognized subspecialties, in addition to skull base, and we used these to develop subspecialty databases of journal citation data. In 2014 we described our method of data retrieval and analysis as applied to pediatric neurosurgery for the application of Bradford's law to identify the core journals of pediatric neurosurgery. ${ }^{30}$ The methods used herein are identical. Scopus was used to identify all original research journal articles (excluding review articles, editorial letters, and so on) for each neurosurgeon, spanning the years 2009-2013. Every article for each author was evaluated to compile data describing the journal publication counts and journal citation counts. Self-citation data were retrieved from Scopus' built-in search and filter functions.

Every effort was made in our database to exclude intradepartmental duplications of publications for those researchers who may share authorship. The researcher with the highest h-index received credit for all publications authored. For the next highest author, any papers coauthored with the first researcher were excluded, but credit was given for all other publications. This sequence was continued until we accounted for all researchers in a given department.

After compiling the databases, we examined the citation list for entries that were not journals (e.g., book chapters, presentations), and these entries were removed. Because these nonjournal entries were removed after exportation from Scopus, the total citations used in describing the cohort are likely to be greater than the final number used in all analyses performed using Bradford's law. The citation databases were constructed from December 2013 to January 2014.

\section{Bradford's Law}

The quantitative relationship between zones relies on a sequence of ratios often described as c:ck:ck for the 
minimal 3-zone pattern, where $\mathrm{c}$ represents the number of journals in Zone 1 and $\mathrm{k}$ represents the Bradford multiplier. The parameter $\mathrm{p}$ represents the number of Bradford zones, which is generally accepted as ranging from a minimum of 3 to a maximum of $10 .^{26}$ The $\mathrm{p}$ parameter also sets the citation target for each zone, because the total number of citations (A) is equally divided into p zones. As an example, suppose there are 6 (c) core journals in a given area of research (Zone 1). If a researcher finds 15 articles of interest in those 6 journals in a month, but requires an additional 12 journals to find 15 more articles of interest (Zone 2), the Bradford multiplier would be 2 (k). For each subsequent 15 articles, a researcher would have to search $24\left(\mathrm{ck}^{2}\right)$ (Zone 3), then $48\left(\mathrm{ck}^{3}\right)$ (Zone 4), then $96\left(\mathrm{ck}^{4}\right)$ (Zone 5) journals, and so on. It is assumed that each field has its own $\mathrm{c}$ and $\mathrm{k}$.

\section{Egghe's Formulation of Bradford's Law of Distribution}

Bradford's law uses 3 parameters to model the c:ck: $\mathrm{ck}^{2}$ ... $\mathrm{ck}^{\mathrm{p}-1}$ sequence using Egghe's formulation. Parameter $\mathrm{c}$ defines the core number of journals. Parameter $\mathrm{k}$ defines the Bradford multiplier. These parameters are dependent on the choice of $p$, which represents the number of zones. They can be solved using the equations below:

$$
\begin{aligned}
& \mathrm{k}=\left(\mathrm{e}^{\gamma} \mathrm{Y}_{\mathrm{m}}\right)^{1 / \mathrm{p}} \\
& \mathrm{c}=\mathrm{T}(\mathrm{k}-1) /\left(\mathrm{k}^{\mathrm{p}}-1\right)
\end{aligned}
$$

The 2 constants in Equation 1, e and $\gamma$, represent Euler's number and Euler's constant, respectively, where $\mathrm{e}^{\gamma}=$ 1.781. $\mathrm{Y}_{\mathrm{m}}$ and $\mathrm{T}$ describe qualities of the database; $\mathrm{Y}_{\mathrm{m}}$ is the number of citations of the highest-ranked journal; and $\mathrm{T}$ is the cumulative number of journals in the database. Using these equations, a theoretical distribution of Bradford zones can be established for a citation database.

Egghe's formulation has been the most widely used derivation of Bradford's law for bibliometric analyses. ${ }^{5}$ Using Egghe's formulation, one can create a graphical representation of Bradford's distribution. The following equations are used for this:

$$
\begin{aligned}
& F(x)=a \log (1+b x) \\
& a=(A / p) / \log k \\
& b=(k-1) / c
\end{aligned}
$$

Each zone of journals should contain the same number of citations $(\mathrm{A} / \mathrm{p})$, where $\mathrm{A}$ is the total number of citations. Additionally, a separate analysis based on Bradford's verbal formulation was performed; the total number of citations was separated into $\mathrm{p}$ zones, and the number of journals in each zone was matched to the appropriate citation density. From these counts of journals, c was given as the count of journals from the first zone, and $\mathrm{k}$ was a common multiplier between zones.

\section{Subspecialty Analysis of Citation Density}

Separate databases were created for each subspecialty.
A cumulative database was also generated from the sum of the individual specialties to determine the core journals for all of neurosurgery. For surgeons who fell within multiple specialties, their citation counts were included for each specialty but were included only once when summing all specialties.

\section{Results}

\section{Participating Academic Neurosurgeons and Cumulative Publication Database}

The database was made up of 150 North American neurosurgeons representing 65 separate academic institutions. The median career h-index was 36 . Over the 5-year period, the mean number of publications per author was 34 and the mean number of journal articles referenced per author was 1183 . The mean number of references per publication per author was 37 . These researchers also had an average self-citation rate of 1.33 per publication (Table 1).

This group of academic neurosurgeons authored 5095 articles in 671 unique journals from 2009 through 2013; these articles included 183,421 total journal article references. The top 10 journals that were most frequently published in were Neurosurgery (627 articles), Journal of Neurosurgery (391), Neurosurgical Focus (234), World Neurosurgery (225), Journal of Neurosurgery: Spine (189), Journal of Neurosurgery: Pediatrics (188), Journal of Neuro-Oncology (148), Spine (114), Journal of Clinical Neuroscience (105), and Epilepsia (84). These 10 journals represented $45 \%$ of the total publications (Table 2).

\section{Egghe's Formulation of Bradford's Law}

The citation database was ranked in descending order of number of citations per journal (Table 3 ). The ranked citation density distribution can be seen in Fig. 2. The number of citations in the top journal, Journal of Neurosurgery, was used as $Y_{m}(13,577)$ and the total number of journals cited was used as $\mathrm{T}$ (7458). Using these values in the previously described Egghe's formulation, we solved for the theoretical citation distribution for 3 to 8 zones (p).

As previously observed in our application of Bradford's law, the citation distribution expected from Egghe's formulation again did not fit the observed citation distribution identified by our citation database (Fig. 3), because Egghe's formulation would predict that all zones carry an approximately equal distribution of citation density, but our distribution did not fit this expectation..$^{30}$ Therefore, Egghe's formulation was again abandoned for the verbal

TABLE 1. Citation metrics for the top 150 neurosurgeons, ranked by $\mathrm{h}$-index*

\begin{tabular}{lc}
\hline \multicolumn{1}{c}{ Citation Metrics } & Cumulative Results for Neurosurgery \\
\hline h-Index & $36.9 / 36(7-76)$ \\
\hline Articles & $34 / 25(1-148)$ \\
\hline Citations in all articles & $1183 / 872(19-8169)$ \\
\hline Citations per publication & $37 / 28(15.17-401)$ \\
\hline Self-citations per paper & $1.33 / 0.97(0-29)$ \\
\hline
\end{tabular}

* Values reported as mean/median (range). 
TABLE 2. The top 10 journals in which the top 150 academic neurosurgeons published from 2009 through 2013

\begin{tabular}{clcc}
\hline Rank & \multicolumn{1}{c}{ Journal } & $\begin{array}{c}\text { No. of } \\
\text { Articles }\end{array}$ & $\begin{array}{c}\text { Cumulative } \\
\% \text { of Total } \\
\text { Articles }\end{array}$ \\
\hline 1 & Neurosurgery & 627 & 12.31 \\
\hline 2 & Journal of Neurosurgery & 391 & 19.98 \\
\hline 3 & Neurosurgical Focus & 234 & 24.57 \\
\hline 4 & World Neurosurgery & 225 & 28.99 \\
\hline 5 & Journal of Neurosurgery: Spine & 189 & 32.70 \\
\hline 6 & Journal of Neurosurgery: Pediatrics & 188 & 36.39 \\
\hline 7 & Journal of Neuro-Oncology & 148 & 39.29 \\
\hline 8 & Spine & 114 & 41.53 \\
\hline 9 & Journal of Clinical Neuroscience & 105 & 43.59 \\
\hline 10 & Epilepsia & 84 & 45.24 \\
\hline
\end{tabular}

formulation of Bradford's law. A comparison of Bradford's verbal law with Egghe's formulation for combined neurosurgery and each subspecialty can be found in Table 4 .

\section{Verbal Formulation of Bradford's Law}

Using this method, we discovered that the distribution followed a pattern for certain values of $\mathrm{p}$. Parameters $\mathrm{c}$ and $\mathrm{k}$ could be found for the first 3 zones that satisfy the verbal formulation, whereas all zones beyond 3 failed to reach the expected citation density for that Bradford multiplier. The closest fit across the first 3 zones was for $p=4$ (Fig. 4). With this formula, the core journals of neurosurgery emerged as the top 8 ranked journals with a Bradford multiplier of 5. The core journals of neurosurgery ranked by citation are as follows: Journal of Neurosurgery, Neurosurgery, Spine, Stroke, Neurology, American Journal of Neuroradiology, International Journal of Radiation Oncology Biology Physics, and New England Journal of Medicine.

\section{Subspecialty Differences in Core Journals}

A Bradford analysis was completed in a similar manner for each subspecialty (Table 5).

\section{Neurosurgical Oncology}

The mean self-citation rate was 0.93 citations/paper (range 0.34-2.13). The verbal formulation of Bradford's law for the neurosurgical oncology group demonstrated 5 journals within the core zone. The core journals as ranked by citation count are Journal of Neurosurgery, Neurosurgery, International Journal of Radiation Oncology Biology Physics, Journal of Neuro-Oncology, and Journal of Clinical Oncology.

\section{Pediatrics}

The mean self-citation rate was 1.28 citations/paper (range 0.11-2.89). As described previously, ${ }^{30}$ the verbal formulation of Bradford's law for the pediatrics group demonstrated 9 journals within the core zone. The core journals as ranked by citation count are Journal of Neurosurgery, Neurosurgery, Epilepsia, Child's Nervous
System, Pediatric Neurosurgery, Neurology, Journal of Neuro-Oncology, Cancer Research, and New England Journal of Medicine.

\section{Peripheral Nerve}

The mean self-citation rate was 0.84 citations/paper (range 0-6.17). The verbal formulation of Bradford's law for the peripheral nerve group demonstrated 10 journals within the core zone. The core journals as ranked by citation count are Journal of Neurosurgery, Neurosurgery, Journal of Hand Surgery, Journal of Bone and Joint Surgery, Spine, Journal of Neuroscience, Experimental Neurology, Neurology, Biomaterials, and Plastic and Reconstructive Surgery.

\section{Skull Base}

The mean self-citation rate was 2.59 citations/paper (range 0-29). The verbal formulation of Bradford's law for the skull base group demonstrated 6 journals within the core zone. The core journals as ranked by citation count are Journal of Neurosurgery, Neurosurgery, Cancer Research, Surgical Neurology, Acta Neurochirurgica, and Journal of Neuro-Oncology.

Spine

The mean self-citation rate was 0.84 citations/paper (range 0-2.24). The verbal formulation of Bradford's law for the spine group demonstrated 3 journals within the core zone. The core journals as ranked by citation count are Spine, Journal of Neurosurgery, and Neurosurgery.

\section{Stereotactic and Functional}

The mean self-citation rate was 1.18 citations/paper (range 0-3.88). The verbal formulation of Bradford's law for the stereotactic and functional group demonstrated 7 journals within the core zone. The core journals as ranked by citation count are Journal of Neurosurgery, Neurosurgery, Epilepsia, Neurology, Journal of Neuroscience, Movement Disorders, and Brain.

\section{Vascular}

The mean self-citation rate was 1.08 citations/paper (range 0.3-2.22). The verbal formulation of Bradford's law for the vascular group demonstrated 3 journals within the core zone. The core journals as ranked by citation count are Stroke, Journal of Neurosurgery, and Neurosurgery.

\section{Discussion}

Bradford's law was used by Madhugiri et al. in 2013 to identify core journals for all of neurosurgery. ${ }^{19}$ The aim of our current study was to further establish the use of Bradford's law in identifying core journals of neurosurgery by using a larger and more diverse sampling method while establishing the core journals for many neurosurgical subspecialties. Using the verbal formulation of Bradford's law, we found 8 journals in the core with a Bradford multiplier of 5 . The core journals of neurosurgery ranked by citation are as follows: Journal of Neurosurgery, Neurosurgery, Spine, Stroke, Neurology, American Journal of Neuroradiology, International Journal of Radiation 
TABLE 3. The top 100 journals ranked by the number of times article citations occur within papers by the top 150 academic neurosurgeons from 2009 through 2013

\begin{tabular}{|c|c|c|c|c|c|}
\hline Rank & Journal & $\begin{array}{l}\text { No. of Times } \\
\text { Cited }\end{array}$ & $\begin{array}{c}\text { Cumulative } \\
\% \text { of Total } \\
\text { Citations }\end{array}$ & $\begin{array}{c}\text { Bradford's } \\
\text { Theoretical \% of } \\
\text { Total Citations }\end{array}$ & $\begin{array}{l}\text { Difference of } \\
\text { Experimental } \\
\text { vs Bradford } \\
\text { Theoretical (\%) }\end{array}$ \\
\hline 1 & Journal of Neurosurgery & 13577 & 7.40 & 14.32 & 48.30 \\
\hline 2 & Neurosurgery & 11983 & 13.94 & 19.94 & 30.12 \\
\hline 3 & Spine & 5006 & 16.66 & 23.51 & 29.11 \\
\hline 4 & Stroke & 4995 & 19.39 & 26.12 & 25.79 \\
\hline 5 & Neurology & 2963 & 21.00 & 28.19 & 25.50 \\
\hline 6 & American Journal of Neuroradiology & 2731 & 22.49 & 29.90 & 24.78 \\
\hline 7 & Int Journal of Radiation Oncology Biology Physics & 2510 & 23.86 & 31.36 & 23.91 \\
\hline 8 & New England Journal of Medicine & 2378 & 25.16 & 32.63 & 22.90 \\
\hline 9 & Acta Neurochirurgica & 2185 & 26.35 & 33.76 & 21.95 \\
\hline 10 & Surgical Neurology & 2122 & 27.51 & 34.77 & 20.89 \\
\hline 11 & Epilepsia & 2107 & 28.65 & 35.68 & 19.70 \\
\hline 12 & Journal of Neuroscience & 1830 & 29.65 & 36.52 & 18.82 \\
\hline 13 & Cancer Research & 1809 & 30.64 & 37.30 & 17.86 \\
\hline 14 & Journal of Neuro-Oncology & 1753 & 31.59 & 38.02 & 16.89 \\
\hline 15 & Journal of Clinical Oncology & 1747 & 32.55 & 38.69 & 15.87 \\
\hline 16 & Neurosurgical Focus & 1732 & 33.49 & 39.31 & 14.81 \\
\hline 17 & Proc of the Natl Academy of Sciences of the USA & 1707 & 34.42 & 39.90 & 13.74 \\
\hline 18 & Cancer & 1631 & 35.31 & 40.46 & 12.73 \\
\hline 19 & Child's Nervous System & 1500 & 36.13 & 40.99 & 11.85 \\
\hline 20 & Nature & 1421 & 36.90 & 41.49 & 11.05 \\
\hline 21 & Brain & 1404 & 37.67 & 41.96 & 10.23 \\
\hline 22 & Journal of Neurology Neurosurgery and Psychiatry & 1358 & 38.41 & 42.42 & 9.45 \\
\hline 23 & Science & 1332 & 39.13 & 42.85 & 8.67 \\
\hline 24 & Lancet & 1318 & 39.85 & 43.27 & 7.89 \\
\hline 25 & Annals of Neurology & 1243 & 40.53 & 43.67 & 7.18 \\
\hline 26 & Radiology & 1056 & 41.11 & 44.05 & 6.68 \\
\hline 27 & Journal of Neurotrauma & 1041 & 41.67 & 44.42 & 6.18 \\
\hline 28 & Journal of Neurosurgery Spine & 1009 & 42.22 & 44.78 & 5.70 \\
\hline 29 & Journal of the American Medical Association & 1001 & 42.77 & 45.12 & 5.21 \\
\hline 30 & Clinical Cancer Research & 882 & 43.25 & 45.45 & 4.84 \\
\hline 31 & Journal of Biological Chemistry & 861 & 43.72 & 45.77 & 4.49 \\
\hline 32 & Brain Research & 856 & 44.19 & 46.09 & 4.12 \\
\hline 33 & Journal of Cerebral Blood Flow and Metabolism & 829 & 44.64 & 46.39 & 3.77 \\
\hline 34 & Pediatric Neurosurgery & 826 & 45.09 & 46.68 & 3.41 \\
\hline 35 & Neuroimage & 825 & 45.54 & 46.97 & 3.04 \\
\hline 36 & Neuroradiology & 809 & 45.98 & 47.24 & 2.67 \\
\hline 37 & Journal of Neurophysiology & 794 & 46.41 & 47.51 & 2.31 \\
\hline 38 & Neuro-Oncology & 764 & 46.83 & 47.77 & 1.98 \\
\hline 39 & Movement Disorders & 762 & 47.24 & 48.03 & 1.63 \\
\hline 40 & British Journal of Neurosurgery & 699 & 47.63 & 48.28 & 1.35 \\
\hline 41 & Archives of Neurology & 684 & 48.00 & 48.52 & 1.07 \\
\hline 42 & Laryngoscope & 659 & 48.36 & 48.76 & 0.82 \\
\hline 43 & European Spine Journal & 654 & 48.71 & 48.99 & 0.56 \\
\hline 44 & Journal of Clinical Endocrinology and Metabolism & 649 & 49.07 & 49.21 & 0.30 \\
\hline 45 & Experimental Neurology & 638 & 49.42 & 49.44 & 0.04 \\
\hline
\end{tabular}


TABLE 3. The top 100 journals ranked by the number of times article citations occur within papers by the top 150 academic neurosurgeons from 2009 through 2013 (continued)

\begin{tabular}{|c|c|c|c|c|c|}
\hline Rank & Journal & $\begin{array}{l}\text { No. of Times } \\
\text { Cited }\end{array}$ & $\begin{array}{l}\text { Cumulative } \\
\% \text { of Total } \\
\text { Citations }\end{array}$ & $\begin{array}{c}\text { Bradford's } \\
\text { Theoretical \% of } \\
\text { Total Citations }\end{array}$ & $\begin{array}{c}\text { Difference of } \\
\text { Experimental } \\
\text { vs Bradford } \\
\text { Theoretical (\%) }\end{array}$ \\
\hline 46 & Cell & 636 & 49.76 & 49.65 & -0.22 \\
\hline 47 & Neurologia Medico Chirurgica & 605 & 50.09 & 49.86 & -0.46 \\
\hline 48 & Stereotactic and Functional Neurosurgery & 603 & 50.42 & 50.07 & -0.70 \\
\hline 49 & Acta Neurochirurgica Supplement & 589 & 50.74 & 50.27 & -0.93 \\
\hline 50 & Journal of Clinical Neuroscience & 588 & 51.06 & 50.47 & -1.17 \\
\hline 51 & Journal of Bone and Joint Surgery Series A & 586 & 51.38 & 50.67 & -1.41 \\
\hline 52 & Critical Care Medicine & 573 & 51.70 & 50.86 & -1.64 \\
\hline 53 & Acta Neuropathologica & 560 & 52.00 & 51.05 & -1.87 \\
\hline 54 & Circulation & 557 & 52.30 & 51.23 & -2.09 \\
\hline 55 & Oncogene & 551 & 52.60 & 51.41 & -2.32 \\
\hline 56 & Neurosurgery Clinics of North America & 539 & 52.90 & 51.59 & -2.54 \\
\hline 57 & Lancet Neurology & 532 & 53.19 & 51.76 & -2.75 \\
\hline 58 & Neuron & 503 & 53.46 & 51.94 & -2.94 \\
\hline 59 & Anesthesiology & 482 & 53.73 & 52.10 & -3.11 \\
\hline 60 & Neuroscience & 479 & 53.99 & 52.27 & -3.29 \\
\hline 61 & Journal of Neurosurgery Pediatrics & 470 & 54.24 & 52.43 & -3.45 \\
\hline 62 & Neurological Research & 468 & 54.50 & 52.59 & -3.62 \\
\hline 63 & Nature Medicine & 463 & 54.75 & 52.75 & -3.79 \\
\hline 64 & Neurosurgical Review & 460 & 55.00 & 52.91 & -3.96 \\
\hline 65 & Clinical Neurology and Neurosurgery & 455 & 55.25 & 53.06 & -4.13 \\
\hline 66 & Clinical Orthopaedics and Related Research & 452 & 55.50 & 53.21 & -4.30 \\
\hline 67 & Magnetic Resonance in Medicine & 439 & 55.74 & 53.36 & -4.46 \\
\hline 68 & Journal of Neuropathology and Experimental Neurology & 434 & 55.97 & 53.50 & -4.61 \\
\hline 69 & Minimally Invasive Neurosurgery & 424 & 56.20 & 53.65 & -4.76 \\
\hline 70 & Journal of Vascular Surgery & 419 & 56.43 & 53.79 & -4.91 \\
\hline 71 & American Journal of Roentgenology & 418 & 56.66 & 53.93 & -5.06 \\
\hline 72 & Neurocritical Care & 413 & 56.88 & 54.07 & -5.21 \\
\hline 73 & PLoS One & 407 & 57.11 & 54.20 & -5.36 \\
\hline 74 & Journal of Immunology & 406 & 57.33 & 54.34 & -5.50 \\
\hline 75 & Journal of Spinal Disorders and Techniques & 403 & 57.55 & 54.47 & -5.65 \\
\hline 76 & Cancer Cell & 379 & 57.75 & 54.60 & -5.78 \\
\hline 77 & Blood & 359 & 57.95 & 54.73 & -5.88 \\
\hline 78 & Clinical Neurosurgery & 348 & 58.14 & 54.86 & -5.98 \\
\hline 79 & Epilepsy Research & 346 & 58.33 & 54.98 & -6.08 \\
\hline 80 & Nature Genetics & 345 & 58.52 & 55.11 & -6.19 \\
\hline 81 & Journal of Trauma Injury Infection and Critical Care & 341 & 58.70 & 55.23 & -6.29 \\
\hline 82 & Journal of Comparative Neurology & 336 & 58.89 & 55.35 & -6.39 \\
\hline 83 & Journal of Neurochemistry & 334 & 59.07 & 55.47 & -6.48 \\
\hline 84 & Clinical Neurophysiology & 331 & 59.25 & 55.59 & -6.58 \\
\hline 85 & International Journal of Cancer & 326 & 59.43 & 55.71 & -6.68 \\
\hline 86 & Otolaryngology Head and Neck Surgery & 325 & 59.60 & 55.82 & -6.78 \\
\hline 87 & British Journal of Cancer & 321 & 59.78 & 55.93 & -6.87 \\
\hline 88 & Nature Neuroscience & 316 & 59.95 & 56.05 & -6.96 \\
\hline 89 & Annals of Surgery & 308 & 60.12 & 56.16 & -7.05 \\
\hline 90 & Journal of Spinal Disorders & 303 & 60.28 & 56.27 & -7.13 \\
\hline
\end{tabular}


TABLE 3. The top 100 journals ranked by the number of times article citations occur within papers by the top 150 academic neurosurgeons from 2009 through 2013 (continued)

\begin{tabular}{|c|c|c|c|c|c|}
\hline Rank & Journal & $\begin{array}{l}\text { No. of Times } \\
\text { Cited }\end{array}$ & $\begin{array}{l}\text { Cumulative } \\
\% \text { of Total } \\
\text { Citations }\end{array}$ & $\begin{array}{c}\text { Bradford's } \\
\text { Theoretical \% of } \\
\text { Total Citations }\end{array}$ & $\begin{array}{l}\text { Difference of } \\
\text { Experimental } \\
\text { vs Bradford } \\
\text { Theoretical (\%) }\end{array}$ \\
\hline 91 & Journal of Neuroscience Research & 299 & 60.45 & 56.38 & -7.21 \\
\hline 92 & Journal of the National Cancer Institute & 298 & 60.61 & 56.49 & -7.30 \\
\hline 93 & Cerebral Cortex & 296 & 60.77 & 56.59 & -7.38 \\
\hline 94 & Journal of Magnetic Resonance Imaging & 292 & 60.93 & 56.70 & -7.46 \\
\hline 95 & Cerebrovascular Diseases & 290 & 61.09 & 56.80 & -7.54 \\
\hline 96 & Canadian Journal of Neurological Sciences & 285 & 61.24 & 56.91 & -7.62 \\
\hline 97 & Molecular Therapy & 282 & 61.40 & 57.01 & -7.70 \\
\hline 98 & American Journal of Pathology & 279 & 61.55 & 57.11 & -7.77 \\
\hline 99 & British Medical Journal & 276 & 61.70 & 57.21 & -7.84 \\
\hline 100 & Journal of Clinical Investigation & 275 & 61.85 & 57.31 & -7.92 \\
\hline
\end{tabular}

Oncology Biology Physics, and New England Journal of Medicine.

Many mathematical approaches exist that apply Bradford's law of scattering to data sets., $4,5,18,26$ This study uses Egghe's expansion of Leimkuhler's method, which has been used in other studies. $5,18,19,26$ This formulation relies on the use of exponential functions to predict zonal distribution and depends on the citation database parameters of total citations by the top journal and the total number of journals; however, no mathematical formulation has achieved consistent statistical significance. ${ }^{9}$ Additionally, how does this type of analysis compare with the more traditional journal ranking that uses the IF? Journal IF is defined as the average number of citations per paper from the prior 2 years of publication. This value is relevant for journals to compare their impact to that of other journals within equivalent fields of study. It is not useful for comparing journals across subjects due to the scope of readership differences. For example, Journal of Neurosurgery and New England Journal of Medicine were both found to

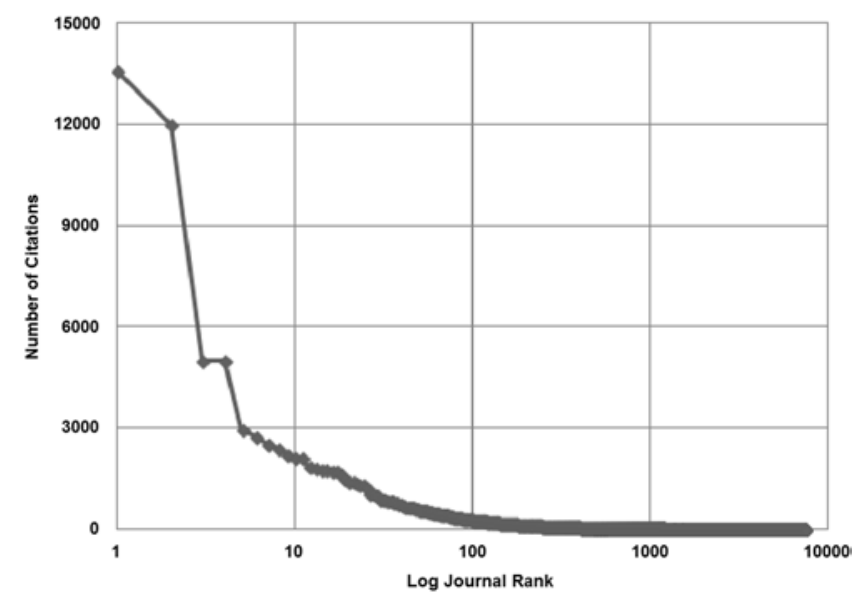

FIG. 2. Citation counts for cumulative database of neurosurgery journals. be core journals for neurosurgery, but their IFs are quite different (3.227 vs 54.42, respectively [2013 IF]). The value of a Bradford's law analysis is that it attempts to analyze utility to a given topic or field regardless of relative overall impact, and is inclusive of journals across traditional field barriers.

Practical application of Bradford's law in neurosurgery may best be applied to neurosurgical subspecialties. Many neurosurgeons have completed fellowships resulting in specialized practices and research interests. An analysis targeted to the major subspecialties would yield more focused and practical results. Additionally, identifying these core journals in neurosurgical subspecialties may also guide medical students, residents, and fellows to the journals that will have the highest impact within their field of interest.

Our sampling method differs from that of Madhugiri et al. ${ }^{19}$ in that rather than sampling articles in neurosurgeryspecific journals (22,850 citations over a 3-month period), we chose to sample all publications from the top 25 neurosurgeons as ranked by h-index for each chosen subspecial-

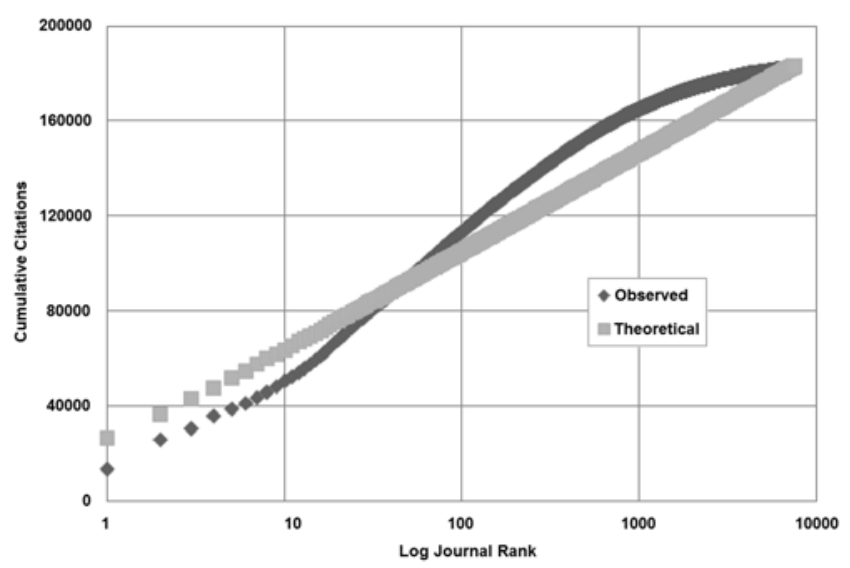

FIG. 3. Graphical comparison of observed data versus Bradford's graphical law for cumulative database of neurosurgery journals. 
TABLE 4. Comparison of 4-zone distribution of Bradford's verbal formulation versus Egghe's theoretical for all of neurosurgery and its subspecialties

\begin{tabular}{|c|c|c|c|c|c|c|c|}
\hline \multirow[b]{2}{*}{ Subspecialty } & \multirow[b]{2}{*}{ Zone } & \multicolumn{3}{|c|}{ Bradford's Verbal Formulation } & \multicolumn{3}{|c|}{ Egghe's Formulation } \\
\hline & & Journals & Citations & $\begin{array}{c}\% \text { Difference } \\
\text { from Theoretical* }\end{array}$ & Journals & Citations & $\begin{array}{c}\% \text { Difference } \\
\text { from Theoretical* }\end{array}$ \\
\hline \multirow[t]{4}{*}{ Combined $†$} & 1 & 8 & 46143 & 0.63 & 4 & 35561 & -22.45 \\
\hline & 2 & 39 & 45738 & -0.26 & 44 & 56923 & 24.14 \\
\hline & 3 & 211 & 45892 & 0.08 & 550 & 63959 & 39.48 \\
\hline & 4 & 7200 & 45648 & -0.45 & 6860 & 26978 & -41.17 \\
\hline \multirow{4}{*}{$\begin{array}{c}\text { Neurosurgical } \\
\text { oncology }\end{array}$} & 1 & 5 & 8016 & -2.41 & 4 & 7256 & -7.30 \\
\hline & 2 & 27 & 7919 & -1.17 & 29 & 8824 & 12.73 \\
\hline & 3 & 141 & 7828 & -0.01 & 242 & 9608 & 22.75 \\
\hline & 4 & 2123 & 7546 & 3.59 & 2021 & 5621 & -28.19 \\
\hline \multirow[t]{4}{*}{ Pediatrics } & 1 & 9 & 6053 & -1.73 & 5 & 4490 & -24.54 \\
\hline & 2 & 36 & 5928 & 0.37 & 37 & 7200 & 21.01 \\
\hline & 3 & 160 & 5944 & 0.10 & 265 & 7557 & 27.01 \\
\hline & 4 & 2026 & 5873 & 1.29 & 1924 & 4551 & -23.51 \\
\hline \multirow[t]{4}{*}{ Peripheral nerve } & 1 & 10 & 1836 & 2.22 & 9 & 1745 & -7.07 \\
\hline & 2 & 44 & 1884 & -0.33 & 43 & 1927 & 2.62 \\
\hline & 3 & 172 & 1877 & 0.04 & 219 & 2147 & 14.34 \\
\hline & 4 & 1151 & 1914 & -1.93 & 1106 & 1692 & -9.89 \\
\hline \multirow[t]{4}{*}{ Skull base } & 1 & 6 & 5996 & -1.46 & 4 & 5269 & -10.84 \\
\hline & 2 & 32 & 5905 & 0.08 & 31 & 6348 & 7.42 \\
\hline & 3 & 163 & 5912 & -0.04 & 246 & 7257 & 22.80 \\
\hline & 4 & 2042 & 5825 & 1.43 & 1963 & 4764 & -19.38 \\
\hline \multirow[t]{4}{*}{ Spine } & 1 & 3 & 6714 & 1.49 & 3 & 6714 & -1.49 \\
\hline & 2 & 43 & 6875 & -0.87 & 31 & 7339 & 7.68 \\
\hline & 3 & 215 & 6809 & 0.10 & 280 & 7937 & 16.45 \\
\hline & 4 & 1995 & 6865 & -0.72 & 2552 & 5273 & -22.64 \\
\hline \multirow{4}{*}{$\begin{array}{l}\text { Stereotactic \& } \\
\quad \text { functional }\end{array}$} & 1 & 7 & 7108 & 2.09 & 6 & 6449 & -11.17 \\
\hline & 2 & 29 & 7240 & 0.27 & 42 & 9306 & 28.19 \\
\hline & 3 & 125 & 7262 & -0.03 & 303 & 8642 & 19.04 \\
\hline & 4 & 2359 & 7429 & -2.33 & 2169 & 4642 & -36.06 \\
\hline \multirow[t]{4}{*}{ Vascular } & 1 & 3 & 11489 & 12.23 & 3 & 11489 & 12.23 \\
\hline & 2 & 22 & 10277 & 0.39 & 27 & 11119 & 8.62 \\
\hline & 3 & 148 & 10234 & -0.03 & 251 & 11594 & 13.26 \\
\hline & 4 & 2084 & 8593 & -16.06 & 2332 & 6746 & -34.10 \\
\hline
\end{tabular}

* Percent difference compares each formulation's value against the theoretical value.

$\dagger$ In a 4-zone model $(p=4)$, the citation count per zone theoretically should be 45,855

ty $(183,421$ citations over a 5-year period from 150 neurosurgeons). These subspecialty databases were combined to evaluate neurosurgery as a whole. These parameters were chosen to construct a database large enough from which to draw meaningful conclusions, yet not broad enough to make data collection and analysis prohibitively labor intensive. Although seemingly arbitrary, any analysis of this type must adhere to specific parameters, because full and detailed sampling of all the neurosurgical literature is simply not possible. This type of sampling technique is not novel to Bradford's law analyses. ${ }^{9,26}$ We chose to sample the citations of highly cited neurosurgeons because it would capture those articles that neurosurgeons cite in journals that-although unconventional to neurosurgery- may be high-impact articles and relevant to their respective subspecialty.

Productivity, in the sense of citation or publication count, is not a guarantee of quality. The h-index does attempt to quantify and measure quality in terms of productivity. An author must continue to publish papers over time (productivity) and have his or her papers cited by peers over time (loosely correlated with quality or, more appropriately, relevance). A citation has been equated to a measure of trust between one author and another regarding the quality of the work. ${ }^{2}$ Therefore, those neurosurgeons who are in the top 25 for each subspecialty as ranked by hindex are presumably currently publishing and citing relevant works in their subspecialty. ${ }^{11,14}$ 
The citation distributions for neurosurgery and its subspecialties did not fit the expected distributions based on currently accepted formulations of Bradford's law. This is an issue common to many other researchers and consistent with previous Bradford's law studies in neurosurgery. ${ }^{10,19,26,30}$ The observed distribution showed a greater number of citations in the central zones than expected, while the first and last zones contained fewer citations. This difference was consistent across subspecialties, although it was most exaggerated for pediatrics, in which the observed distribution was furthest from the model. Neurosurgery as a whole is a broad field encompassing most of the other subspecialties. Not surprisingly then, Egghe's expected distribution as applied to neurosurgery as a whole most resembles the pediatrics distribution.

It has recently been suggested that highly interdisciplinary fields will produce a Bradford distribution with increased scatter, or similar to the distribution previously discussed. When a subject or field is highly interdisciplinary, the distribution of the information relevant to that field or subject will be scattered across a greater number of journals, diminishing the strength of the core journals while inflating the secondary zones. The highly interdisciplinary nature of neurosurgery may account for the distribution observed within neurosurgical literature. ${ }^{9}$ The concept of interdisciplinarity and its impact on the production of scientific literature has only recently been described by Hjørland..$^{9,10,21}$ Continued research on interdisciplinarity and its impact on the distribution of scientific literature is needed.

The differences in the distribution of the observed data and the expected model distribution may also be explained by the journals that make up each zone. The core zones for each subspecialty of neurosurgery are all different, but Journal of Neurosurgery and Neurosurgery are represented in the core of all neurosurgical specialties, ranking as the first and second journal, respectively, for all subspecialties except spine and vascular, for which they are second and third. These journals represent the most specific and inclusive journals of neurosurgery. The central zones contain some journals that, although less specific, traditionally have a higher impact with a much broader scope. These journals represent a smaller number of articles, but by virtue of the IF of these journals, they may be highly impactful. An analysis of the impact a specific research article has on a journal or zone was beyond the scope of this study.

How does this work affect the average neurosurgeon? The rapid expansion of scientific literature is likely to continue, making it even more difficult for general and subspecialty neurosurgeons to keep abreast of all pertinent research being published monthly or quarterly. We have shown that many journals with broader readership or that traditionally are nonneurosurgical, like New England Journal of Medicine, are publishing highly cited works that are having an impact within our field. Kondziolka responded to the article by Madhugiri et al. in which he calls into question the current structure of the flow of knowledge (i.e., article submission/peer review/publication/citation) as "fundamentally flawed." 16 There are many other avenues that clinician researchers can use to stay up to date on current research. These include conferences, advanced courses, journal clubs, teaching sessions for residents and

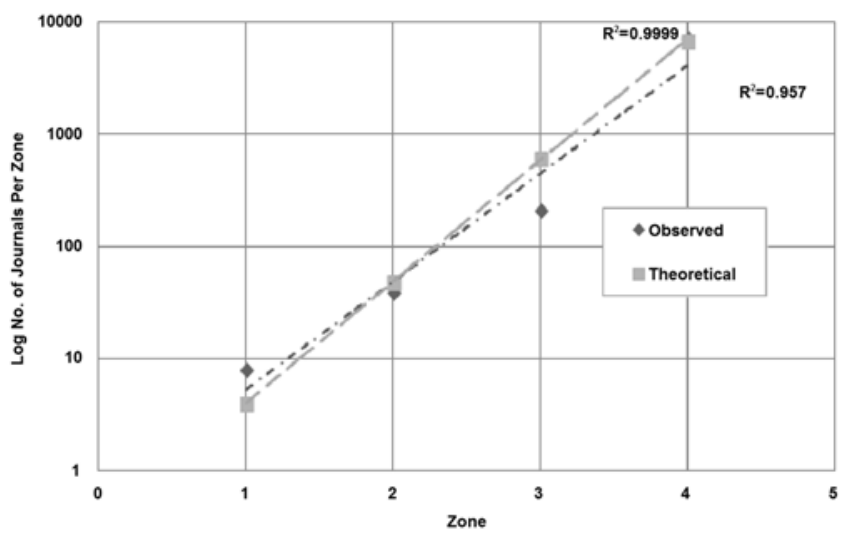

FIG. 4. Zonal citation distribution of Bradford's verbal formulation versus observed.

fellows, electronic resources, and even our patients themselves. This paper serves to identify the core journals in the various neurosurgical subspecialties based on the academic productivity of the top-producing North American neurosurgeons. By identifying the core journals for each neurosurgical subspecialty, we believe readership can be directed to those journals most likely to have a consistently high impact while not overlooking those journals that may be traditionally nonneurosurgical but that may contain a smaller number of especially high-impact articles.

\section{Limitations}

This study can only be as accurate as the database used to complete it (i.e., Scopus). Scopus may have multiple entries for some researchers based on variations in name reporting. These entries generally included few or singular publications that may or may not have met our inclusion criteria and were not included in this analysis. With such a large sample size (183,421 citations), we considered the lack of these entries to be negligible. The export utility in Scopus is limited to 160 rows of data, and thus, the inclusion criteria were broken into smaller partitions to accommodate this limitation; however, when viewing all citations used by an author, Scopus eliminates duplicate references, and by exporting smaller partitions of the whole, some of these duplications may have been included.

Although Bradford's law was originally intended to be used for complete databases, ${ }^{3}$ the rapid expansion of scientific literature makes the application to broad topics, such as neurosurgery, impractical. ${ }^{28}$ However, by limiting the amount of literature sampled, the possibility of introducing selection bias exists. One such bias may be regional preference of journals from which authors choose to cite. We previously analyzed the potential for such bias within pediatric neurosurgery. ${ }^{30}$ When comparing journal preferences for citations based on region, we found that although the top journal differed between North American and European pediatric neurosurgeons, there was considerable homogeneity when looking at the core journals from each group. Therefore, this study represents the core journals for North American neurosurgery, but probably has impact for practitioners in other regions. Additionally, senior 
TABLE 5. Cumulative and subspecialty-specific core journals*

\begin{tabular}{|c|c|c|c|c|c|c|c|c|}
\hline \multirow[b]{2}{*}{ Rank } & \multirow[b]{2}{*}{ Combined } & \multicolumn{7}{|c|}{ Subspecialty } \\
\hline & & $\begin{array}{c}\text { Neurosurgical } \\
\text { Oncology }\end{array}$ & Pediatrics & $\begin{array}{l}\text { Peripheral } \\
\text { Nerve }\end{array}$ & Skull Base & Spine & $\begin{array}{c}\text { Stereotactic \& } \\
\text { Functional }\end{array}$ & Vascular \\
\hline 1 & $\begin{array}{l}\text { Journal of Neu- } \\
\text { rosurgery }\end{array}$ & $\begin{array}{l}\text { Journal of } \mathrm{Neu}- \\
\text { rosurgery }\end{array}$ & $\begin{array}{l}\text { Journal of } \mathrm{Neu}- \\
\text { rosurgery }\end{array}$ & $\begin{array}{l}\text { Journal of } \mathrm{Neu}- \\
\text { rosurgery }\end{array}$ & $\begin{array}{l}\text { Journal of } \mathrm{Neu}- \\
\text { rosurgery }\end{array}$ & Spine & $\begin{array}{l}\text { Journal of } \mathrm{Neu}- \\
\text { rosurgery }\end{array}$ & Stroke \\
\hline 2 & Neurosurgery & Neurosurgery & Neurosurgery & Neurosurgery & Neurosurgery & $\begin{array}{l}\text { Journal of } \mathrm{Neu}- \\
\text { rosurgery }\end{array}$ & Neurosurgery & $\begin{array}{l}\text { Journal of Neu- } \\
\text { rosurgery }\end{array}$ \\
\hline 3 & Spine & $\begin{array}{l}\text { Int Journal of } \\
\quad \text { Radiation } \\
\text { Oncol- } \\
\text { ogy Biology } \\
\text { Physics }\end{array}$ & Epilepsia & $\begin{array}{l}\text { Journal of Hand } \\
\text { Surgery }\end{array}$ & $\begin{array}{l}\text { Cancer Re- } \\
\text { search }\end{array}$ & Neurosurgery & Epilepsia & Neurosurgery \\
\hline 4 & Stroke & $\begin{array}{l}\text { Journal of } \\
\text { Neuro- } \\
\text { Oncology }\end{array}$ & $\begin{array}{l}\text { Child's Nervous } \\
\text { System }\end{array}$ & $\begin{array}{l}\text { Journal of Bone } \\
\text { and Joint } \\
\text { Surgery }\end{array}$ & $\begin{array}{l}\text { Surgical Neu- } \\
\quad \text { rology }\end{array}$ & - & Neurology & - \\
\hline 5 & Neurology & $\begin{array}{l}\text { Journal of Clini- } \\
\text { cal Oncology }\end{array}$ & $\begin{array}{c}\text { Pediatric Neu- } \\
\text { rosurgery }\end{array}$ & Spine & $\begin{array}{l}\text { Acta Neuro- } \\
\text { chirurgica }\end{array}$ & - & $\begin{array}{l}\text { Journal of Neu- } \\
\text { roscience }\end{array}$ & - \\
\hline 6 & $\begin{array}{l}\text { American } \\
\text { Journal of } \\
\text { Neuroradiol- } \\
\text { ogy }\end{array}$ & - & Neurology & $\begin{array}{l}\text { Journal of Neu- } \\
\text { roscience }\end{array}$ & $\begin{array}{l}\text { Journal of } \\
\text { Neuro- } \\
\text { Oncology }\end{array}$ & - & $\begin{array}{l}\text { Movement } \\
\text { Disorders }\end{array}$ & - \\
\hline 7 & $\begin{array}{l}\text { Int Journal of } \\
\text { Radiation } \\
\text { Oncol- } \\
\text { ogy Biology } \\
\text { Physics }\end{array}$ & - & $\begin{array}{l}\text { Journal of } \\
\text { Neuro- } \\
\text { Oncology }\end{array}$ & $\begin{array}{r}\text { Experimental } \\
\text { Neurology }\end{array}$ & - & - & Brain & - \\
\hline 8 & $\begin{array}{c}\text { New England } \\
\text { Journal of } \\
\text { Medicine }\end{array}$ & - & $\begin{array}{l}\text { Cancer Re- } \\
\text { search }\end{array}$ & Neurology & - & - & - & - \\
\hline 9 & - & - & $\begin{array}{c}\text { New England } \\
\text { Journal of } \\
\text { Medicine }\end{array}$ & Biomaterials & - & - & - & - \\
\hline 10 & - & - & - & $\begin{array}{l}\text { Plastic and Re- } \\
\text { constructive } \\
\text { Surgery }\end{array}$ & - & - & - & - \\
\hline
\end{tabular}

* Dashes represent a space where no journal is present; each subspecialty has a different number of core journals.

researchers may have preferences for which journals they choose to cite (i.e., more established journals with higher IFs vs newer, open access journals), which may influence the results of this analysis. More studies are needed to analyze citation preference between various academic ranks. Finally, this study may be limited by self-citation, as with any study of citation (h-index, journal IF, and so on). The mean and range of self-citation rates for the top 25 academic neurosurgeons in each subspecialty are reported.

\section{Conclusions}

Bradford's law of distribution has been underapplied to fields of academic medicine. We present the first core journal analysis for neurosurgical subspecialties and an expanded look at the core journals for all of neurosurgery. Although each subspecialty has its own unique core of journals, Journal of Neurosurgery and Neurosurgery are among the core journals for all subspecialties. We propose that the current core journals for neurosurgery ranked by citation are as follows: Journal of Neurosurgery, Neurosurgery, Spine, Stroke, Neurology, American Journal of Neuroradiology, International Journal of Radiation Oncology Biology Physics, and New England Journal of Medicine.

\section{Acknowledgment}

We thank Andrew J. Gienapp (Department of Medical Education, Methodist University Hospital, and Department of Neurosurgery, University of Tennessee Health Science Center, Memphis, TN) for technical and copy editing, preparation of the manuscript and figures for publishing, and publication assistance with this manuscript.

\section{References}

1. Aoun SG, Bendok BR, Rahme RJ, Dacey RG Jr, Batjer HH: Standardizing the evaluation of scientific and academic performance in neurosurgery-critical review of the " $h$ " index 
and its variants. World Neurosurg 80:e85-e90, 2013

2. Bar-Ilan J: Informetrics at the beginning of the 21 st century-A review. J Informetrics 2:1-52, 2008

3. Bradford S: Sources of information on specific subjects. Engineering 137:85-86, 1934

4. Brookes BC: Bradford's law and the bibliography of science. Nature 224:953-956, 1969

5. Egghe L: Applications of the theory of Bradford's Law to the calculation of Leimkuhler's Law and to the completion of bibliographies. J Am Soc Inf Sci 41:469-492, 1990

6. Fell DW, Burnham JF, Buchanan MJ, Horchen HA, Scherr JA: Mapping the core journals of the physical therapy literature. J Med Libr Assoc 99:202-207, 2011

7. Franchignoni F, Muñoz Lasa S: Bibliometric indicators and core journals in physical and rehabilitation medicine. J Rehabil Med 43:471-476, 2011

8. Hirsch JE: An index to quantify an individual's scientific research output. Proc Natl Acad Sci U S A 102:16569-16572, 2005

9. Hjørland B: Practical potentials of Bradford's law: a critical examination of the received view. J Doc 63:359-377, 2007

10. Hjørland B, Nicolaisen J: Bradford's law of scattering: ambiguities in the concept of "subject", in Crestani F, Ruthven I (eds): Information Context: Nature, Impact, and Role. Berlin: Springer, 2005, pp 96-106

11. Kalra RR, Kestle JR: An assessment of academic productivity in pediatric neurosurgery. J Neurosurg Pediatr 12:262265,2013

12. Khan N, Thompson CJ, Choudhri AF, Boop FA, Klimo P Jr: Part I: The application of the h-index to groups of individuals and departments in academic neurosurgery. World Neurosurg 80:759-765, 765.e1-765.e3, 2013

13. Khan NR, Thompson CJ, Taylor DR, Gabrick KS, Choudhri AF, Boop FR, et al: Part II: Should the h-index be modified? An analysis of the m-quotient, contemporary h-index, authorship value, and impact factor. World Neurosurg 80:766-774, 2013

14. Khan NR, Thompson CJ, Taylor DR, Venable GT, Wham RM, Michael LM II, et al: An analysis of publication productivity for 1225 academic neurosurgeons and 99 departments in the United States. J Neurosurg 120:746-755, 2014

15. Klimo P Jr, Venable GT, Khan NR, Taylor DR, Shepherd BA, Thompson CJ, et al: Bibliometric evaluation of pediatric neurosurgery in North America. J Neurosurg Pediatr 14:695-703, 2014

16. Kondziolka D: Core journals. J Neurosurg 119:1271-1273, 2013

17. Lee J, Kraus KL, Couldwell WT: Use of the h index in neurosurgery. Clinical article. J Neurosurg 111:387-392, 2009

18. Leimkuhler F: The Bradford distribution. J Doc 23:197-207, 1967

19. Madhugiri VS, Ambekar S, Strom SF, Nanda A: A technique to identify core journals for neurosurgery using citation scatter analysis and the Bradford distribution across neurosurgery journals. J Neurosurg 119:1274-1287, 2013

20. Price DJ: Networks of scientific papers. Science 149:510515,1965
21. Sayama H, Akaishi J: Characterizing interdisciplinarity of researchers and research topics using web search engines. PLoS One 7:e38747, 2012

22. Scheckler WE: A realistic journal reading plan. The cornerstone of continuing medical education. JAMA 248:19871988, 1982

23. Smith DR: Identifying a set of 'core' journals in occupational health, part 2: lists derived by bibliometric techniques. Arch Environ Occup Health 65:173-175, 2010

24. Smith DR: A longitudinal analysis of bibliometric and impact factor trends among the core international journals of nursing, 1977-2008. Int J Nurs Stud 47:1491-1499, 2010

25. Spearman CM, Quigley MJ, Quigley MR, Wilberger JE: Survey of the $h$ index for all of academic neurosurgery: another power-law phenomenon? J Neurosurg 113:929-933, 2010

26. Sudhier KG: Application of Bradford's Law of Scattering to the physics literature: a study of doctoral theses citations at the Indian Institute of Science. DESIDOC J Libr Inform Technol 30:3-14, 2010

27. Tague J, Beheshti J, Rees-Potter L: The law of exponential growth: Evidence, implications, and forecasts. Libr Trends 30:125-149, 1981

28. Tenopir C, King DW, Clarke MT, Na K, Zhou X: Journal reading patterns and preferences of pediatricians. J Med Libr Assoc 95:56-63, 2007

29. Venable GT, Khan NR, Taylor DR, Thompson CJ, Michael LM, Klimo P Jr: A correlation between National Institutes of Health funding and bibliometrics in neurosurgery. World Neurosurg 81:468-472, 2013

30. Venable GT, Shepherd BA, Roberts ML, Taylor DR, Khan NR, Klimo P Jr: An application of Bradford's law: identification of the core journals of pediatric neurosurgery and a regional comparison of citation density. Childs Nerv Syst 30:1717-1727, 2014

\section{Disclosure}

The authors report no conflict of interest concerning the materials or methods used in this study or the findings specified in this paper.

\section{Author Contributions}

Conception and design: Klimo, Venable, Shepherd. Acquisition of data: all authors. Analysis and interpretation of data: Klimo, Venable, Shepherd. Drafting the article: Klimo, Venable, Shepherd. Critically revising the article: all authors. Reviewed submitted version of manuscript: all authors. Approved the final version of the manuscript on behalf of all authors: Klimo. Statistical analysis: Venable, Shepherd. Study supervision: Klimo.

\section{Correspondence}

Paul Klimo Jr., Semmes-Murphey Neurologic \& Spine Institute, 6325 Humphreys Blvd., Memphis, TN 38120. email: pklimo@ semmes-murphey.com. 